\title{
La Doctrina de Prescripción en el Derecho Internacional Público y la necesidad de nuevos paradigmas transnacionales
}

\author{
The Doctrine of Prescription in Public International Law \\ and the necessity of new transnational paradigms
}

\author{
Pedro J. MartíneZ-Fraga \\ Profesor de Derecho \\ Universidad de Nueva York (Estados Unidos) \\ pedro.martinezfraga@bryancave.com
}

Resumen: El derecho internacional consuetudinario tiene en un -aparentemente- irreconciliable conflicto sobre una cuestión tan fundamental como si reconoce en el derecho internacional un equivalente a las leyes nacionales sobre prescripción extintiva. A modo de ejemplo, sólo 132 de los aproximadamente 3000 tratados bilaterales y multilaterales de protección de inversiones vigentes tienen un período de prescripción. El balance teóricamente permitiría la presentación de reclamaciones obsoletas a perpetuidad o de otro modo injertos con base aleatoria en períodos ad hoc de prescripción. Por lo tanto, la falta de uniformidad y de regulaciones estándares han dado lugar a la incertidumbre y a la inseguridad: los mismos que la propia doctrina sobre el período de prescripción pretende erradicar. El autor afirma que el estado fragmentado del derecho internacional público con respecto a la doctrina sobre el período de prescripción es atribuible a: (i) la importación a gran escala de leyes nacionales-domésticas sobre prescripción extintiva al derecho internacional público, sin haber considerado las políticas y aspiraciones del derecho internacional; y (ii) a las agendas económicas de los países industrializados, con exclusión de los intereses de los países en desarrollo y las economías en transición. Una metodología descriptiva y prescriptiva es aplicada en el desarrollo de esta propuesta.

Palabras clave: derecho internacional consuetudinario, prescripción extintiva, tratados de inversión extranjera.
Abstract: International customary law presents an (apparently) irresoluble conflict on a central issue as the existence in International law of an equivalent of the national laws on equivalent to national laws on prescription. For instance, only 132 over approximately 3000 bilateral and multilateral investment treaties include a statute of limitations. Theoretically, the balance would allow to indefinitely present outdated complaints or, alternatively, to introduce them on a random basis in ad hoc prescription periods. Therefore, lacks of uniformity and standard regulations have determined uncertainty and insecurity: the very same problems that the statute of limitations' doctrine aims to eradicate. The author states public International law fragmentation on the prescription period's doctrine lays on: (i) massive enclosure of domestic legislation on statute of limitations into public International law disregarding International law politics and aspirations; and (ii) industrialised States' economic agendas, ruling out developing countries and transitional economies. In order to develop the present proposal a descriptive and prescriptive methodology is applied.

Keywords: International customary law, prescription, investment treaties, investment treatie.

Sumario: I. INTRODUCCIÓN. II. EL ESTATUS DE LA DOCTRINA DE PRESCRIPCIÓN EXTINTIVA EN EL DERECHO INTERNACIONAL CONSUETUDINARIO. A. El caso Gentini. B. El caso Williams. C. La paradoja y el legado de los casos de los tribunales de reclamaciones. III. EL DERECHO INTERNACIONAL CONSUETUDINARIO Y UNA DOCTRINA SOBRE EL PERIODO DE PRESCRIPCIÓN QUE ES INTERNAMENTE INCONSISTENTE: LA NECESIDAD DE UNIFORMIDAD Y POLIITICA. A. De acuerdo con los laudos con base en tratados no existe en el Derecho Internacional Público el equivalente a un periodo de prescripción diferente al contenido de un tratado. IV. LOS TRIBUNALES ARBITRALES EN ARBITRAJES ENTRE INVERSORES Y ESTADOS INTENTAN MITIGAR LAS CONSECUENCIAS DE UN ANÁLISIS DE LA PRESCRIPCIÓN CON BASE EN LA LEY NACIONAL. A. Hechos que transcienden al periodo de prescripción. B. Análisis del daño continuado. C. Un estándar de razonabilidad puede ser discernido con respecto a los periodos de prescripción en el Derecho Internacional Público. V. Un cambio de paradigma con base en las políticas del Derecho Internacional Público de protección de inversiones. A. Un enfoque prescriptivo. CONCLUSIONES. Anexo. TRATADOS EN VIGOR CON PLAZOS DE PRESCRIPCIÓN EXTINTIVA 
«Any map of the world that does not include Utopia is not even worth glancing at.»

Oscar Wilde

The Soul of Man Under Socialism

\section{INTRODUCCIÓN}

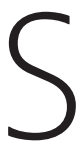
olo 132 de los aproximadamente 3.000 tratados bilaterales y multilaterales de protección de inversiones vigentes contemplan un período de prescripción. El balance teóricamente permitiría la presentación de reclamaciones obsoletas a perpetuidad o de otro modo injertos con base aleatoria de períodos ad hoc de prescripción. Esta falta de uniformidad y regulaciones estándares ha dado lugar a la incertidumbre y a la inseguridad: la misma que la propia doctrina sobre el período de prescripción (LPD, por sus siglas en inglés, derivadas de limitations period doctrine) trata de erradicar. El autor afirma que la situación fragmentada del derecho internacional público con respecto a la LPD es atribuible a (i) la importación al por mayor de leyes nacionales-domésticas sobre prescripción extintiva al derecho internacional público, sin haber considerado las políticas y aspiraciones del derecho internacional, y (ii) a las agendas económicas de los países industrializados con exclusión de los intereses de los países en desarrollo y las economías en transición. Una metodología descriptiva y prescriptiva se aplica en el desarrollo de esta propuesta.

Este marco se desarrolla mediante la exploración de cuatro secciones que examinan diferentes fuentes normativas materiales para el desarrollo de la LPD en el derecho internacional público en general y que tienen un efecto consecuente sobre el derecho internacional sobre la protección de inversiones, en particular. En primer lugar, se analiza la LPD en el derecho internacional consuetudinario, a través de la lente de dos casos emblemáticos, el caso Gentini y el caso Williams, así como el legado más general de los Tribunales de Reclamaciones sobre el tratamiento de la LPD en el derecho internacional consuetudinario. En segundo lugar, se realiza un breve análisis sobre la necesidad de uniformidad y de una política estándar derivada de los laudos dictados con base en tratados. Se examina hasta qué punto las políticas que regulan la LPD en el derecho internacional público eliminan el tener que recurrir a principios generales que se derivan históricamente de marcos nacionales-domésticos. En este caso se sostiene que los principios jurídicos nacionales-domésticos rela- 
tivos a períodos de prescripción no tienen cabida en el derecho internacional de protección de la inversión y sólo sirven para arrebatar la uniformidad y el valor predictivo de los trabajos teóricos y prácticos de la LPD. En tercer lugar, la forma en que los tribunales arbitrales en arbitrajes entre inversores y Estados han intentado mitigar las consecuencias de la aplicación de la ley nacional-doméstica, por ejemplo, ampliando los plazos pertinentes más allá del período de prescripción causando un continuo daño a la teoría al prolongar un, de por sí, inadecuado término de prescripción, e ideando la creación de un estándar de «razonabilidad». En cuarto lugar, se propone un cambio de paradigma. Esta reconceptualización de la LPD en el marco del derecho internacional de la protección de la inversión tiene base fundamentalmente en (i) la comprensión de los períodos de prescripción en el derecho internacional como completamente separados de los principios y doctrinas de su contraparte nacional-doméstica; (ii) un reconocimiento de la dualidad (un híbrido de los preceptos tanto sustantivos como procedimentales) de la LPD; (iii) la sugerencia de metodologías para la uniformidad del injerto y, por tanto, para promover la certeza y seguridad; y (iv) el análisis de quince proposiciones, no exhaustivas, con base en las políticas y los objetivos de la legislación internacional sobre protección de inversiones que puedan servir para armonizar los intereses de los Estados exportadores e importadores de capital. En esta sección final se esboza una presunción refutable como parte del esfuerzo por usar la LPD para nivelar el campo de juego entre los Estados exportadores e importadores de capital.

\section{EL ESTATUS DE LA DOCTRINA DE PRESCRIPCIÓN EXTINTIVA EN EL DERECHO INTERNACIONAL CONSUETUDINARIO}

Los pronunciamientos, no basados en tratados, conformados por: (i) decisiones judiciales; (ii) laudos arbitrales; y (iii) resoluciones de los Tribunales de Reclamaciones, describen mejor, si no es que constituyen en su totalidad, los elementos normativos del derecho internacional consuetudinario ${ }^{1}$. La

1 Aunque el Art. 38 del Estatuto de la Corte Internacional de Justicia (CIJ), la fuente más autorizada para determinar el derecho internacional consuetudinario, enumera las «decisiones judiciales» como parte del derecho internacional consuetudinario; sin embargo, el artículo no menciona el papel de los laudos arbitrales en el derecho internacional consuetudinario. (Ver, v.g., Gilbert Guillaume, H., Precedent in International Arbitration, Can Arbitral Awards Constitute a 
constitución teórica y la aplicación práctica de la LPD en el derecho internacional público que ha influido en el papel de la doctrina sobre el derecho internacional de protección de la inversión, puede ser recogida en un puñado de importantes pronunciamientos sobre el tema ${ }^{2}$, que tuvieron lugar en un período de veinte años entre 1885 y 1905 . Esta jurisprudencia ofrece una perspectiva única porque su tratamiento de la LPD no tiene base en un período de prescripción contenido en un tratado. Por lo tanto, representa los paradigmas -perfectamente ordenados- de los Tribunales de Reclamaciones para abordar el tema de la prescripción libre de los grilletes conceptuales de cualquier tratado.

\section{A. El caso Gentini}

El caso Gentini, una historia que se ha contado muchas veces, no obliga a una larga recitación fáctica. ${ }^{3}$ Baste decir que el caso se refería a reclamaciones contra Venezuela por parte del Gobierno italiano en nombre de un ciudadano italiano, exigiendo el pago de una deuda que se había causado treinta años antes. ${ }^{4}$ El caso fue presentado ante el Corte Permanente de Arbitraje (CPA) de conformidad con la Comisión Mixta de Reclamaciones Italiano-Venezolana constituida el 7 de mayo de 1903. El caso es particularmente rico pues al examinar los argumentos de los Comisionados de las partes (los abogados presentado sus respectivos casos) el Árbitro analiza un espectro bastante amplio de

Source of International Law under Article 38 of the ICF Statute? 105 (Yas Banifatime y Emmanuel Gaillard [eds.], Nueva York, Juris Publishing Inc. 2008)).

El papel de los laudos arbitrales en el derecho internacional consuetudinario no es claro, en parte, debido a la naturaleza $a d$ boc de los tribunales arbitrales inversor-Estado formados después de que surge la disputa y se configuran exclusivamente durante la vida de una sola disputa. De hecho, los laudos arbitrales sólo constituyen una autoridad persuasiva con respecto a los tribunales subsiguientes que tramitan las mismas cuestiones legales o similares. (MARTíNEZ-FrAGA, P.J., A Defense of Dissents in Investment Arbitration, 43 U. Miami Inter-Am. L. Rev. 445, 465-66, 2012).

2 Caso de fohn H. Williams c. Venezuela (1885); Caso de Ann Eulogia García Cádiz (Loretta G. Barberie) c. Venezuela (1885); Caso Odoardo Gentini c. Venezuela (1903); Caso de William C. Spader et al. c. Venezuela (1903); Caso Irene Roberts c. Venezuela (1903-1905); y el Pious Fund entre los Estados Unidos y México (1902).

3 Ver Cheng, B., General Principles of Law as Applied by International Courts and Tribunals 37879 (George W. Keeton y Georg Schwarzenberger [eds.], Cambridge University Press 2006) (1953). Ver también Jackson H Ralston, Prescription, 4 Am. J. Int'l L. 1 (ene. 2010). Ver también Wena Hotels c. Egipto, párr. 106-107.

4 Gentini, p. 554. 
los escritos de comentaristas y «precedentes» que pretenden abordar el papel, si lo hubiere, de la LPD en el derecho internacional. El Árbitro niega la reclamación como obsoleta, pero ciertamente no sin antes de articular su propia exégesis en cuanto a cuatro (4) fuentes separadas, pero igualmente vinculantes, que en opinión del Árbitro, invitan a la desestimación de la reclamación.

En primer lugar, el Árbitro trató de distinguir la defensa de Venezuela en Gentini de la de México en el caso de Pious Fund, que había sido decidido anteriormente por la $\mathrm{CPA}^{5}$. El arbitro destacó el Pious Fund enfatizando que el tribunal en ese caso estaba dirigiéndose a las reglas domésticas y no a los principios de la ley, de modo que en el Pious Fund el argumento decía: «La Corte Permanente de Arbitraje... nunca negó el principio de prescripción, un principio bien reconocido en el derecho internacional, y es justo creer que nunca lo haría» [énfasis añadido] ${ }^{6}$. El Árbitro agregó que «tal negación tiende a molestar a todo gobierno, ya que el poder sobre las áreas determinadas depende de la posesión santificada por la prescripción, aunque las circunstancias de su origen y el tiempo que debe transcurrir pueda variar en cada caso» ${ }^{7}$.

Este argumento tan formal que escogió solo una oración de la totalidad de la opinión del Pious Fund, en un esfuerzo por alcanzar una posición diametralmente opuesta, estaba comprensiblemente apoyado en una vasta depen-

5 De hecho, el abogado de Italia se apoyó en Pious Fund para afirmar que la ausencia de una doctrina del derecho internacional de prescripción relativa a una reclamación contra un Estado hace que sea conceptualmente imposible para un reclamante presentar una reclamación. Al encontrar apoyo analítico en Pious Fund, los abogados de Italia argumentaron:

No requirió un largo argumento del honorable agente de los Estados Unidos para obtener de la corte un decreto de pago de México, incluyendo esta máxima: Les règles de la prescription étant exclusivement du domaine du droit civil, ne sauraient être appliquées au présent conflit entre les deux États en litige.

Este principio es además absolutamente lógico y moral, ya que cuando se trata de créditos y débitos privados se puede presumir que el que ha permitido el lapso de un largo período sin presentar sus derechos ante el tribunal puede haber tenido la intención de renunciar a ellos; o puede admitirse que debe sufrir los resultados de su negligencia. Idem., vid., p. 553.

6 El argumento se construyó sobre un estricto análisis lingüístico que, aunque técnicamente correcto, desafía el espíritu de la opinión del Pious Fund. El Árbitro observó:

Cabe señalar que la declaración del tribunal no se refería al principio de prescripción, sino a las normas que le rodeaban el derecho civil. Una «règle», como se nos dice en el Dictionnaire des Synonymes de Bourguignon \& Bergerol - est essentiellement pratique et, de plus, obligatoire***; il est des règles de l'art comme des règles de gouvernement, mientras que principio (principe) exprime une vérité générale, d'après laquelle on dirige ses actions, qui sert de base théorique aux divers actes de la vie, et dont l'application à la 7 Idem. réalité amène telle ou telle conséquence. $I d$. p.t 556. 
dencia de las obras de publicistas que se remontan a Grotius y Vico. ${ }^{8}$ El árbitro luchó entre articular la proposición de que, de algún modo, la LPD tenía un espacio reconocible en el derecho internacional, y la aplicación de ese principio, particularmente, a raíz de la decisión del Pious Fund. En segundo lugar, las desestimaciones de defensas que tenían base en un «precedente» en el que los Tribunales de Reclamaciones habían desechado reclamaciones obsoletas. Ninguna de las autoridades en las que el Árbitro fundamentó sus conclusiones en particular trató de distinguir entre la aplicación de la doctrina en virtud del derecho internacional y su funcionamiento en un marco jurídico nacional-doméstico9. Por el contrario, el Árbitro, citando a Barberie c. Venezuela, la autoridad más ampliamente utilizada en el dictamen, selecciona el lenguaje de esa sentencia que subraya que el derecho nacional-doméstico debe servir de guía para la aplicación de la doctrina en el contexto de un tratado internacional:

Un reclamo obsoleto no lo es menos porque resulta ser internacional, y este tribunal, al tratar con él, no puede escapar a la obligación de un principio universalmente reconocido simplemente porque no existe un código de reglas positivas por el cual su acción debe ser gobernada. [Énfasis original] ${ }^{10}$.

8 La confianza del árbitro en la autoridad de los publicistas ciertamente compite con el artículo 38 del estatuto de la CIJ. Más importante aún, subrayó la necesidad percibida de complementar el déficit analítico endémico a cualquier esfuerzo para tratar de distinguir su caso del marco del Pious Fund. Este análisis, sin embargo, también fue formal, es decir, una mera recitación de nombres y no una prospección de principios doctrinales sobre el tema: las expresiones de muchos escritores de derecho internacional sobre este punto, incluyendo Wheaton, Vattel, Phillimore, Hall, Poison, Calvo , Vico, Grotius, Taparelli, Sala, Coca-Cola, Sir Henry Maine, Brocher, Domat, Burke. Wharton y Markby, se recopilan en el caso de Williams c. Venezuela, Comisión de Reclamaciones Venezolano-Americana de 1888, citada extensamente en 4 Moore, página 4181. A ellos podemos añadir Bello, quien en la página 42 de su Derecho Internacional, dice:

La prescripción es aún más importante y necesaria entre las naciones que entre los individuos, como que las desavenencias de aquellas tienen resultados harto más graves, acarreando muchas veces la guerra.

$9 \quad$ Id. pp. 559-561.

10 Idem p. 560.

Esta proposición se opone enérgicamente a los argumentos que los abogados de Italia habían presentado anteriormente en favor de los reclamantes en Gentini. Específicamente, el abogado argumentó que la doctrina de las prescripción en un contexto internacional debía modificarse y distinguirse de su contraparte nacional-doméstica por motivos que eran legítimamente convincentes:

Sin embargo, cuando el deudor es un gobierno y, además, cuando la demanda del individuo puede ser objeto de un reclamo, las razones que pueden inducir a un acreedor a posponer su acción pueden ser muchas y de naturaleza variada; como, por ejemplo, la interrupción de las relaciones diplomáticas entre los gobiernos interesados, la falta de influencia política del acreedor, las condiciones financieras desfavorables del gobierno 
Por tanto, el uso de esta decisión debilita aún más el poder gravitatorio de Pious Fund sobre Gentini.

Tercero, el Árbitro considera que la legislación nacional-doméstica, incluso la de las jurisdicciones que no son parte, es útil para su causa. Citando a los tribunales de equidad en Inglaterra y los Estados Unidos, en particular a Boubier, el Árbitro se refiere a cómo:

Los tribunales de equidad, aunque no dentro de los términos del estatuto, se han conformado uniformemente en su espíritu y, por regla general, se han regido por sus disposiciones, a menos que circunstancias especiales de fraude o similares requieran, en el interés de la justicia, que deban ser ignorados. (12 Pet., 56; 130 U.S., 43, etc.) Los tribunales de equidad aplicarán el estatuto por analogía y, en los casos de competencia concurrente, estarán obligados por los estatutos que rigen las acciones legales. (149 U.S., 436; 169 US, 189). Algunas demandas, no prohibidas por el estatuto, un tribunal de equidad no las hará cumplir debido a la política pública y la dificultad de hacer justicia completa cuando la transacción está oscurecida por el paso del tiempo y la pérdida de pruebas. Esto se denomina la doctrina de los laches ${ }^{11}$.

Esta tercera fuente, tribunales nacionales que aplican la equidad, está estrechamente relacionada, pero aún así diferenciada de las cuatro premisas en las que se basa la desestimación de la reclamación: un argumento con base en la equidad derivado de una comprensión muy particular de la justicia y la ética asociada a la LPD. A modo de ejemplo, el Árbitro menciona cómo «así parece que los tribunales de equidad, aun cuando no estaban obligados por el estatuto, a reconocer su justicia esencial, lo han seguido [la aplicación de la LPD] en espíritu» ${ }^{12}$. De hecho, más allá de una necesidad práctica percibida, la opinión caracteriza la LPD como «leyes de aplicación universal que no eran actos arbitrarios de poder, sino que... eran el resultado de un sentimiento general de que la equidad exigía su promulgación $\gg^{13}$.

En consecuencia, Gentini proporciona evidencia histórica de que al menos los Tribunales de Reclamaciones bajo los auspicios del antecesor de la CIJ,

deudor, El acreedor en la imparcialidad de los magistrados, que, desprotegidos por el sentimiento de permanencia, pudieran contra su mejor juicio convertirse en herramientas flexibles de un partido y muchos otros motivos similares. Idem., vid., p. 553.

11 Idem p. 558. Laches, se puede traducir como: demora excesiva en la presentación de un reclamo, que puede resultar en la inadmisibilidad de la acción.

12 Idem.

13 Idem p. 557. 
la CPA en 1903, identifican que la aplicabilidad de un período de prescripción en el derecho internacional podría tener sus fundamentos normativos en: (i) los escritos de publicistas; (ii) precedentes en la forma de laudos de los Tribunales de Reclamaciones otorgados en conjunción con la CPA; (iii) la práctica nacional-doméstica de los tribunales de equidad en Inglaterra y los Estados Unidos; y (iv) las más generales proposiciones de «ley natural» que surgen de concepciones específicas de justicia, equidad y de un pretendido «entendimiento compartido». En este sentido, la contribución de Gentini al desarrollo de la LPD en el derecho internacional puede considerarse como una contribución a la comprensión moderna de la doctrina con base en: (i) el derecho nacional (sentido de que la finalidad es apropiada); (ii) una proposición general de que la finalidad es necesaria; y (iii) el precepto ético-moral de que, de alguna manera, es incorrecto o negligente que una reclamación no se presente dentro de un período de tiempo no especificado y quizás indefinible.

El análisis de Gentini pinta el retrato perfecto de la herencia sobre LPD identificada en este escrito que es omnipresente en el derecho internacional moderno sobre protección de la inversión. Es un paradigma de la doctrina con base en principios de derecho nacional-doméstico, con componentes intuitivos que son puramente viscerales, que enfatizan la política de certeza y finalidad en detrimento de otras consideraciones endémicas al derecho internacional. Asimismo, describe una doctrina que está materialmente influenciada por las agendas económicas de los Estados exportadores de capital. Por omisión, el razonamiento y contenido en Gentini también es elocuente en cuanto a las cuestiones generales que deben subyacer en cualquier consideración sobre la aplicación de la doctrina en un contexto de derecho internacional: sobre todo, las políticas incidentes en cualquier rama particular del derecho internacional. En aras de la integridad, merece destacar que, a pesar del razonamiento categórico y la conclusión del Árbitro de que la doctrina encuentra un lugar en el derecho internacional, incluso cuando el tratado aplicable es silencioso sobre la cuestión, el laudo así, aunque tímidamente, en un momento califica el hallazgo afirmando que, en cuanto al período de prescripción a aplicarse «las circunstancias de su origen y el tiempo que debe transcurrir pueden variar en cada caso» ${ }^{14}$ [énfasis añadido].

Irónicamente, los argumentos desechados, presentados por el representante legal de Italia en Gentini, eran más progresistas, clarividentes y relevantes con respecto al desarrollo y la aplicación de una LPD en un contexto de

14 Idem, p. 556. 
derecho internacional. El representante de Italia argumentó que las políticas que subyacen en la aplicación de la LPD en los asuntos nacionales-domésticos no eran transferibles al ámbito del derecho internacional ${ }^{15}$. A pesar de que el abogado enmarcó estos argumentos en los términos de la controversia sustantiva en cuestión en el caso Gentini, el principio general de su afirmación es fundamentalmente la necesidad de tener diferentes análisis de LPD, vinculados a la rúbrica del derecho nacional e internacional, respectivamente. El Árbitro nunca tomó en consideración tales premisas.

\section{B. El Caso Williams}

En Williams c. Venezuela ${ }^{16}$, como en Gentini, un soberano, en este caso los Estados Unidos de América, presentó una reclamación en nombre de un ciudadano estadounidense contra Venezuela alegando dinero adeudado. La acción fue interpuesta ante la Comisión Americano-Venezolana ${ }^{17}$, tal como en Gentini, bajo los auspicios de la CPA. El incontrovertido expediente estableció que «la reclamación no fue llevada a la atención del Gobierno venezolano, sino hasta veintiséis años después de su inicio» ${ }^{18}$ [énfasis añadido]. La cuestión ante la Comisión de Reclamaciones fue enmarcada en dos oraciones. Si «por el transcurso del tiempo los medios de defensa habían sido deteriorados, y si hay una total ausencia de excusa para el largo retraso del demandante». En tales circunstancias, ¿qué exige la ley en nuestras manos?» ${ }^{19}$ $\mathrm{Al}$ hacerlo, el Tribunal de Reclamaciones observó que «más allá del requisito de que sus decisiones sean ajustadas a la justicia, el tratado no proporciona guía alguna a la comisión sobre el lapso de tiempo para la extinción de las obligaciones. Se deja a la dirección del derecho internacional la solución del tema. ¿Reconoce la doctrina tal extinción entre Estados en controversias como ésta? ${ }^{20}$ [énfasis añadido].

15 Supra, n. 5.

16 El caso de Fohn H. Williams c. Venezuela, decisión del Comisionado, Sr. Little, Moore (ed.), History and Digest of the International Arbitrations to Which the United States has been a Party, vol. IV, 4199 (John Bassett ed., Washington: Government Printing Office 1898).

17 La Comisión de Reclamaciones establecida en virtud del Convenio celebrado entre los Estados Unidos de América y Venezuela el 5 de diciembre de 1885.

18 Idem, p. 280.

19 Idem.

20 Idem. 
La Comisión de Reclamaciones respondió afirmativamente a esta segunda pregunta. Por consiguiente, con respecto a la interrogante anterior se desprende que estaba justificado el sobreseimiento de la demanda. El caso de Williams concluye que el derecho internacional prevé un período de prescripción incluso en ausencia de un tratado que contenga cualificación de la prescripción, con base en dos fuentes: (i) los escritos de los comentaristas, y (ii) en gran parte el derecho común interno de los Estados Unidos. De hecho, prácticamente todo el cuerpo del laudo del Comisionado Little está compuesto por resúmenes -de un solo párrafo- de los escritos de juristas sobre el tema de la LPD, trazando los contornos de cuatro siglos de escritos sobre el tema. Después de sintetizar estos escritos, el Comisionado concluyó que «al examinar detenidamente las autoridades sobre el tema, gran parte de cuya discusión sólo es remotamente aplicable a la pregunta tal como se nos presenta, somos de la opinión de que, por su decidido peso, podría decirse que por necesidad misma, la prescripción tiene un lugar en el sistema internacional y debe considerarse en estas adjudicacione» ${ }^{21}$ [énfasis añadido].

Resulta notable que la Comisión de Reclamaciones califique aún más su conclusión señalando que los principios reconocidos en los escritos son «generales» y por lo tanto, al menos presumiblemente a primera vista, no aplicables «a las reclamaciones individuales o a las deudas de un Estado por razón de transacciones con ciudadanos de otro Estado» ${ }^{22}$. Aunque consciente de este desafío conceptual básico, el Comisionado lo concilia a los fines de la adjudicación y rechaza la reclamación con base en que la prescripción se fundamenta en el derecho natural, una formulación que impregna los escritos de prácticamente todos los juristas citados en el laudo ${ }^{23}$.

El laudo de Williams sirvió como base conceptual para el análisis y la decisión de Gentini. Ambos fundamentalmente importan para el análisis del derecho internacional de la LPD desde la ley doméstica y el derecho natural. En

21 Idem, p. 290.

22 Idem.

23 Vid., en general, R. Phillimore; «Esta [prescripción de derecho público] es, en principio, muy parecida a la prescripción del derecho privado, la cual de hecho puede calificarse de modelo del uso del derecho público y cuyo uso surgió de la razón de la cosa...».

Calvo: «¿Pueden la usucapión y la prescripción ser consideradas en relación con los pueblos y los Estados como medios regulares y normales de adquirir bienes?» Si se admite que estas dos formas de adquisición son legítimas y basadas en la ley natural, se está lógicamente obligado a admitir que son igualmente conformes a los principios del derecho de las naciones, y deben aplicarse a las naciones». Idem pp. 281-82. 
cualquier caso ¿el Comisionado o el Árbitro trataron de buscar una respuesta a su pregunta fundamental en el derecho internacional? ¿El derecho internacional reconoce la LPD en circunstancias en que el tratado en cuestión no contiene tal calificación? Por el contrario, los análisis se centraron en la legislación nacional y en los comentarios con base principalmente en una conceptualización de la ley natural de la doctrina. Otros casos del Tribunal de Reclamaciones durante este período (1885-1905) aplicaron la misma metodología. ${ }^{24}$

\section{La paradoja y el legado de los casos de los Tribunales de Reclamaciones}

Gentini y Williams pueden interpretarse como partidarios de que el derecho internacional, sin especificar un campo en particular del mismo, reconoce y alienta la aplicación de la LPD incluso cuando el tratado en cuestión no señala un período de prescripción extintiva. La contribución al funcionamiento de la LPD en derecho internacional derivada de estos casos influyó en la falta de uniformidad que actualmente caracteriza el estatus de una LPD en el derecho internacional público en general y con respecto al derecho internacional de protección de la inversión en particular. Una reflexión más cercana es necesaria.

Los casos de los Tribunales de Reclamaciones extrajeron de los escritos de los juristas que la LPD es virtualmente sacrosanto, porque hace posible la seguridad y la certeza como un objetivo. El argumento se amplió para decir que tal seguridad y certeza también evitaría disputas territoriales entre las naciones, así como contribuiría a la estabilidad de las transacciones comerciales. Con respecto a este último punto, se argumentó que se produciría un caos si todos los contratos estuviesen sujetos a impugnación a pesar del paso del tiempo, eso sin contar que pudiesen ser rescindidos. Por lo tanto, el principio de seguridad fue consagrado y se le asignó un peso determinante en cualquier cálculo relacionado con la aplicación de la doctrina. Sin embargo, los casos de los Tribunales de Reclamaciones, paradójicamente, socavaron y desautorizaron los mismos principios de seguridad y certeza que buscaba fomentar conforme a la LPD. Al confiar en la ley natural, sin más, los laudos de los Tribunales de Reclamaciones contribuyeron a una fragmentada jurisprudencia de derecho internacional sobre la cuestión, muy básica, de si la LPD se aplica al derecho internacional consuetudinario o al derecho internacional convencional en los

24 Vid., n. 9. 
casos en que un tratado es silencioso sobre el tema. La jurisprudencia con base en el derecho natural hizo posible el salto del derecho nacional-doméstico al derecho internacional, pero sólo en unos términos generales que no establecieron límites. En consecuencia, los laudos de los Tribunales de Reclamaciones crearon un período de prescripciones abiertas en el derecho internacional. Indican la aplicación de la LPD, pero omiten establecer un marco de tiempo real para las prescripciones. De hecho, en la misma autoridad y cita específica en las que el Comisionado del caso Williams confió, se demuestran las deficiencias implícitas del análisis estricto de la ley natural que se observó:

Taparelli:

De ahí la ley de prescripción -una ley necesaria y justa- mediante la cual la sociedad detiene, a través de ciertas limitaciones, todas las inquisiciones de derechos antiguos.

Por lo tanto, lo más razonable es la ley de prescripción en el orden natu$\mathrm{ral}$, aunque la propia naturaleza no establezca abiertamente su estricta necesidad ni fije sus propias limitaciones. Esto debe ser realizado por la sociedad a medida que crece más y es más perfecta... (Ley Natural, vol. 2, 979.) p. 282 [énfasis añadido].

La omisión es probablemente atribuible a dos factores. En primer lugar, desde un punto de vista práctico, la resolución de las reclamaciones que contenían registros indiscutibles del paso de más de dos décadas, al igual que las cuestiones a las que se enfrentan los Tribunales de Reclamaciones, no obligaban al tribunal a ir más lejos y articular un período de prescripción aplicable, un límite real. A los Tribunales de Reclamaciones no se les pidió que hicieran tal pronunciamiento, y es comprensible que ellos no lo hicieran sua sponte.

En segundo lugar, si los Tribunales de Reclamaciones hubiesen formulado una norma que estableciese un límite al período de prescripción que se aplicase al caso como una cuestión de «derecho internacional establecido», de conformidad con su metodología heredada, o hubiese tenido que recurrir a las normas nacionales-domésticas para la asistencia analítica. De hecho, los Tribunales de Reclamaciones se basaron en la ley nacional-doméstica para obtener el fundamento analítico para llegar a la proposición incondicional de que el derecho internacional reconoce la LPD. El uso de la legislación nacionaldoméstica para elaborar una regla de prescripción con un plazo real de años, habría llevado más precipitadamente a la falta de uniformidad y coherencia conceptual que ahora está presente en el derecho internacional sobre el tema.

Recurrir a la legislación nacional-doméstica a los efectos de la formulación de un plazo de años que se aplicará a una regla de presunción de derecho 
internacional conduciría a la creación de normas diferentes, dependiendo de la legislación nacional del Estado que sea demandado en una controversia particular. Por lo tanto, llevado a sus consecuencias lógicas, sólo por mera casualidad estadística, surgiría una regla de prescripciones consistente. La mera coincidencia estadística constituiría así el fundamento normativo de la uniformidad.

$\mathrm{El}$ análisis necesario que habría llevado a la formación de un sistema uniforme nunca se llevó a cabo, y aún no se ha abordado. Exigiría un cambio de paradigma de la ley nacional-doméstica. Este análisis invitaría a la consideración de cuestiones relacionadas con las políticas de derecho internacional, que son separadas y distintas de las del derecho nacional-doméstico y sólo interceptan cuestiones generales que se consideran bajo cualquier rúbrica.

Los casos de los Tribunales de Reclamaciones nos dejan con una regla de ley que declara que el derecho internacional consuetudinario reconoce que la LPD se aplica a las controversias relativas a tratados que omitieron cualquier referencia a esa doctrina. Ninguna construcción alternativa de esta máxima es posible. Esta proposición, sin embargo, entra en conflicto directo y explícito con la autoridad contemporánea bajo la forma de laudos arbitrales derivados de arbitrajes entre inversores y Estados. Estos laudos arbitrales sostienen que el derecho internacional consuetudinario no reconoce la LPD y, además, afirman que tal doctrina sólo forma parte del derecho internacional convencional en los casos en que el tratado en cuestión contiene una cláusula de período de prescripción.

\section{El DERECHO INTERNACIONAL CONSUETUDINARIO Y UNA DOCTRINA SOBRE EL PERÍODO DE PRESCRIPCIÓN QUE ES INTERNAMENTE INCONSISTENTE: LA NECESIDAD DE UNIFORMIDAD Y POLÍTICA}

Desde una perspectiva netamente descriptiva, la situación actual del LPD en el derecho internacional consuetudinario es incierta. Esta incertidumbre, desde una perspectiva descriptiva, surge de un conflicto demostrable entre el trabajo de los publicistas ${ }^{25}$ y los casos de los Tribunales de Reclamaciones que representan una línea de autoridad muy específica, y el criterio sostenido en sentencias arbitrales, derivadas de arbitrajes entre inversores y Estados con base en tratados. Los casos de los Tribunales de Reclamaciones sostuvieron de manera uniforme que el derecho internacional consuetudinario reconoce y

25 Supra, n. 8. 
aplica la LPD en los casos relativos a controversias con base en tratados, cuando el tratado en cuestión carece de referencia a un período de prescripciones ${ }^{26}$. Los laudos arbitrales estipulan que el derecho internacional convencional reconoce y aplica la LPD en los casos relativos a arbitrajes basados en tratados en los cuales el tratado en cuestión contiene un período de prescripción. Afirman además que el derecho internacional consuetudinario no reconoce la LPD.

Estas declaraciones contradictorias quizás pueden conciliarse mediante una distinción y añadiendo que los laudos arbitrales se refieren al derecho internacional público de la protección de las inversiones, mientras que los escritos de los publicistas y los casos de los Tribunales de Reclamaciones no hacen esa calificación. De hecho, puede afirmarse que los casos de los Tribunales de Reclamaciones se refieren principalmente a controversias territoriales o a conflictos derivados de transacciones comerciales que no se refieren en absoluto a las normas de protección de inversiones. A pesar de su atractivo superficial, esta explicación es desmentida por los propios laudos arbitrales. Estos laudos sostienen que es el derecho internacional consuetudinario en general y no respecto a ningún campo particular, donde la LPD no encuentra espacio alguno ${ }^{27}$. Los laudos arbitrales que se refieren a la LPD no establecen una distinción entre el derecho internacional consuetudinario, el derecho internacional y el derecho internacional de protección de inversiones. ${ }^{28}$ Por lo tanto, los laudos arbitrales no pueden distinguirse de los casos de los Tribunales de Reclamaciones sobre esa base. El problema es más complejo. Lo mismo ocurre con la solución.

\section{A. De acuerdo con los Laudos con Base en Tratados No Existe en el Derecho Internacional Público el Equivalente a un Período de Prescripción Diferente al Contenido en un Tratado}

En una reclamación surgida en virtud del Acuerdo de Promoción y Protección de Inversiones (APPRI) suscrito entre Lituania e Italia, el Tribunal rechazó la defensa de prescripción extintiva alegada por la demandada (Lituania) observando que «contrariamente a lo que afirma la demandada, la reclamación

26 Supra bajo «La paradoja y el legado de los casos de los Tribunales de Reclamaciones» p. 11

27 Vid. infra n. 35, refiriendose a Ergoalians TOB c.Moldova.

28 Vid. Luigiterzo Bosca c. La Republica de Lituania, CPA Caso No. 2011-05, en p. 120, CNUDMI (2013); así como en Gavazzi c. Rumania, CIADI Caso No. ARB/12/25 (Decisión sobre Jurisdicción, Admisibilidad y Responsabilidad) (2015). 
del demandante no está sujeta a la prescripción lituana. De conformidad con el acuerdo, el Tribunal aplica el derecho internacional, no el derecho interno lituano, a estos procedimientos y no hay fecha límite establecida por el Acuerdo, las normas o los principios generales del derecho internacional ${ }^{29}$ [énfasis añadido]. Más aun, en ese caso, el Tribunal sostuvo que era razonable que el reclamante hubiese esperado para iniciar un arbitraje hasta que se concluyese el litigio pendiente ante los tribunales de Lituania, concerniente a la privatización objeto del $\operatorname{arbitraje}^{30}$. El Tribunal señaló específicamente que «el demandante notificó a la demandada su intención de iniciar el arbitraje en 2007, cuando el litigio en los tribunales lituanos relativo a la privatización de Alita estaba en curso. A juicio del Tribunal, no era razonable esperar que esas decisiones fueran adoptadas para emprender un procedimiento separado en un marco internacional $\gg^{31}$. Así, el Tribunal concluyó que «el reclamo del Demandante [era] admisible» ${ }^{32}$.

De la misma manera, el Tribunal en Gavazzi c. Rumanía, Caso CIADI $\mathrm{n}^{\mathrm{o}} \mathrm{ARB} / 12 / 25$ (Decisión sobre competencia, admisibilidad y responsabilidad) (2015) rechazó la defensa de prescripción expuesta por la demandada y declaró que «los procedimientos arbitrales están regidos por el derecho internacional, y solo el derecho internacional -y no ninguna ley interna- pueden introducir plazos de prescripción. [Cita omitida] Ni el Convenio CIADI, ni el APPRI, ni el derecho internacional en general contienen ningún plazo de prescripción en relación con los reclamos de tratados. Sin esas claras disposiciones legales, no puede aplicarse ningún límite de tiempo [prescripción] para impedir un arbitraje en CIADI» ${ }^{33}$ [énfasis añadido].

Esta decisión reitera la proposición de que no existe un período equivalente a la prescripción en el derecho internacional público o en el marco del Convenio del CIADI, salvo que esté presente en un tratado. Además, dado que el derecho internacional regula los procedimientos basados en tratados, se impide a un demandado confiar en períodos de prescripción nacionalesdomésticos para evitar el enjuiciamiento de tales reclamaciones.

Debido a la ausencia de una contrapartida internacional al período de prescripción interno dentro de la rúbrica del derecho internacional consue-

\footnotetext{
29 Bosca en p. 120.

30 El laudo no discutió hasta qué punto el proceso judicial incluía partes idénticas, causas de acción, tema y petición a ser resarcida.

31 Idem.

32 Idem en p. 121.

33 Gavazzi en p. 147.
} 
tudinario, las reivindicaciones basadas en tratados se rigen por el plazo de prescripción extintiva contenido en el tratado en cuestión.

Esta línea de criterio -o autoridad-simplemente no puede conciliarse con los casos de los Tribunales de Reclamaciones. Por lo tanto, el estado actual de la LPD en el marco del derecho internacional público no podría ser más incierto, conceptualmente hablando. Una línea de autoridad, los casos de los Tribunales de Reclamaciones junto con algunos publicistas, sostiene que el derecho internacional consuetudinario reconoce y aplica la LPD en disputas basadas en un tratado que guarda silencio en cuanto a un período de prescripción ${ }^{34}$. Una segunda línea de autoridad, igualmente normativa, sostiene que el derecho internacional consuetudinario no reconoce la LPD en las disputas basadas en un tratado, cuando el mismo es silencioso en cuanto a un período de prescripción ${ }^{35}$. La configuración fragmentada y la ausencia de fundamentos doctrinales sólidos, más allá de la dependencia del derecho interno nacional y las políticas que favorecen los intereses de los Estados exportadores de capital, han llevado a los tribunales a buscar fórmulas improvisadas. Tres son las más notables.

\section{LOS TRIBUNALES ARBITRALES EN ARBITRAJES ENTRE INVERSORES Y ESTADOS INTENTAN MITIGAR LAS CONSECUENCIAS DE UN ANÁLISIS DE LA PRESCRIPCIÓN CON BASE EN LA LEY NACIONAL}

En primer lugar, una serie de laudos arbitrales han sostenido que, en los casos en que el tratado en cuestión contiene un período de prescripción, pueden considerarse hechos que vayan más allá del plazo de dicho período ${ }^{36}$. Esta aparente, pero no real, expansión del término de prescripción para in-

34 Supra, n. 14.

35 Vid. Nagel c. República Checa, Cámara de Comercio de Estocolmo, no 049/2002, Laudo Definitivo, párr. 334 (9 de septiembre de 2003), el cual señala: «El Tribunal Arbitral concluye que respecto a la reclamación derivada de un tratado internacional, las normas de prescripción del derecho interno no son directamente pertinentes y que habría que aplicar normas internacionales». Ver también Ergoalians TOB c. Moldavia, CNUDMI, Laudo, párr. 122 (23 de octubre de 2013), donde se indica que «el tribunal concluye que cuando se trata de prescripciones relativas a reclamaciones en virtud de tratados de inversión, el derecho doméstico en cuanto a prescripción no se aplica, sino que se aplica el derecho internacional a la determinación de la prescripción pertinente, y no existe tal ley bajo el derecho internacional que se aplicaría a las reclamaciones en virtud del Tratado de la Carta de la Energía».

36 Ver Grand River Enterprises Six Nations, Ltd., et al. c. Estados Unidos de América, CNUDMI, Decisión sobre las objeciones a la jurisdicción, párr. 86 (20 de julio de 2006), dice en parte: 
corporar hechos más allá del término, busca contextualizar premisas fácticas dentro del período de prescripción. Es una admisión de que un período de prescripción nacional-doméstico es simplemente inadecuado en un tratado. En segundo lugar, algunos tribunales han adoptado una teoría de «daño continuado» similar a la «doctrina de daño continuado extracontractual» (continuing tort doctrine) del derecho consuetudinario de los Estados Unidos, que amplía el período de prescripción mucho más allá del término de tres (3) años. ${ }^{37}$ En tercer lugar, otros tribunales han tratado de recurrir a un «análisis de razonabilidad» para ir más allá de las restricciones impuestas por la importación del análisis del período de prescripción correspondiente a la ley nacional-doméstica ${ }^{38}$.

Existen además unos hechos que trascienden el periodo de prescripción considerado:

1) $\mathrm{Al}$ menos un tribunal ha opinado que la configuración fáctica única que se asocia a la denuncia de un tratado por Denegación de Justicia exige un período de prescripción más flexible, en Eli Lilly and Company contra el Gobierno de Canadá, CNUDMI, Case No. UNCT/14/2 (2017). Allí el Tribunal, al tratar las fechas pertinentes para el comienzo de un período de prescripción en una acción en la que se cuestionaba la invalidación judicial de patentes, señalaba que «el demandante no sufrió, y no pudo haber sufrido, la pérdida de que se queja aquí» (es decir, la invalidación de las Patentes Zyprexa y Strattera) antes de que dichas patentes fueran invalidadas» ${ }^{39}$. En efecto, el Tribunal concluyó que los hechos siguientes a la fecha en que la Corte Suprema [de Canadá] negó la autorización del demandante para apelar la invalidación de las patentes de Strattera y de Zyprexa se ubican dentro del período

En el caso Mondev, el Tribunal consideró (y rechazó) la afirmación de la Demandante de que había sufrido una denegación de justicia en relación con procedimientos judiciales estatales que se produjeron después de la entrada en vigencia del TLCAN, aunque la disputa surgió años atrás. En Feldman, el Tribunal otorgó daños y perjuicios por discriminación durante el período de tres años de limitación, pero su análisis de esta y otras reclamaciones requirió nuevamente la consideración de hechos anteriores [énfasis añadido].

37 Dos años después de la primera generación de APPRIs, la constelación internacional de APPRIs y tratados con provisiones de inversión, refleja un incremento de estos instrumentos hasta exactamente 563. De estos 563 APPRIs y TPIs, ninguno contenía un período de prescripción. El período de limitación promedio contenido en los APPRIs y en los TPIs es un período de tres (3) años (ver el cuadro Anexo A de este escrito.).

38 Vid., v.g., Wena Hotels c. Egipto, and Alan Craig c. Ministry of Energy of Iran.

39 Idem en p. 168. 
de prescripción de tres (3) años establecido en los Artículos 1116 (2) y 1117 (2) del TLCAN ${ }^{40}$.

2) El laudo en Eli Lilly también refuerza la proposición de que, al menos en el marco de los tribunales del TLCAN, los reclamantes pueden confiar en hechos predicados más allá del período de prescripción como parte de una reclamación viable:

172. En este contexto, muchos tribunales anteriores del TLCAN han encontrado apropiado considerar acontecimientos anteriores que proporcionan los antecedentes fácticos para una reclamación oportuna. Según lo declarado por el tribunal en Glamis Gold c. Estados Unidos, se permite a un reclamante citar 'predicados fácticos' que ocurren fuera del período de prescripción, aunque no sean necesariamente la base legal para su reclamación. [Cita omitida] El tribunal de Grand River c. Estados Unidos llegó a la misma conclusión, basándose en decisiones anteriores:

'Los tribunales de Mondev y Feldman consideraron el mérito de las reclamaciones en relación con los hechos ocurridos durante el período de prescripción de tres años, aunque estuvieran vinculados a eventos previos al período de prescripción o a la entrada en vigor del TLCAN. En el caso Mondev, el Tribunal consideró (y rechazó) la afirmación de la Demandante de que había sufrido una denegación de justicia en relación con procedimientos judiciales estatales que se produjeron después de la entrada en vigencia del TLCAN, aunque la disputa surgió años atrás. En Feldman, el Tribunal otorgó daños y perjuicios por discriminación durante el período de tres años de prescripción, pero su análisis de ésta y otras reclamaciones requirió nuevamente la consideración de hechos anteriores'. [Cita omitida]. ${ }^{41}$

40 Idem en párr. 170. También vale la pena señalar que párr. 159 el Tribunal en Eli Lilly and Company reconoció que el derecho internacional público rechaza una teoría continua de la responsabilidad extracontractual. Esta posición no estaba completamente desarrollada, ni existía una autoridad que apoyase tal sugerencia. Por el contrario, varios tribunales habían identificado diferentes permutaciones de esta teoría. El lenguaje exacto del Tribunal Eli Lilly merece ser revisado:

El Tribunal toma nota de las observaciones de la Demandada, México y los Estados Unidos en las que se establece que el plazo de prescripción en virtud de los Artículos 1116 (2) y 1117 (2) no está sujeta a suspensión, prórroga u otra calificación y que, en particular, una conducta continua del Estado no puede detener o echar atrás el reloj de la prescripción. En el presente caso, el Demandante no ha presentado una teoría de la continuidad del incumplimiento ni propugnó la suspensión o la prórroga del plazo de prescripción. Tampoco el Tribunal adopta tal enfoque para llegar a su decisión. Este caso es más sencillo: el alegado incumplimiento para cada inversión -la invalidación de la patente- ocurrió en un solo punto del tiempo dentro del plazo de tres años [énfasis añadido].

${ }^{41}$ Idem en párr. 172. 
La necesidad de ir más allá de un período de tres años de prescripción en una disputa internacional es impulsada por muchos factores, ${ }^{42}$ entre los cuales se encuentra la propia naturaleza de las inversiones internacionales. Una característica destacada de una inversión internacional que desencadena normas de protección con base en tratados, es la longevidad. ${ }^{43}$ Muchas de esas inversiones, si no la mayoría, tienen efectos microeconómicos e incluso macroeconómicos. Por lo tanto, los análisis de Eli Lilly, Mondev y Feldman son comprensibles, pero no son tan completos como para abordar las deficiencias derivadas de un análisis del legado nacional-doméstico.

\section{A. Análisis del daño continuado}

A pesar de los dictámenes emitidos por el Tribunal en Eli Lilly, hay una nota de pie de página de la cual se puede inferir que una «teoría de daño continuado» no encuentra espacio en el derecho internacional público, sin embargo, esa proposición está en conflicto directo y explícito con análisis más sostenidos sobre el tema.

Quizás el examen más relevante de la «jurisprudencia» sobre la cuestión de la oportunidad o momento en el contexto del TLCAN se encuentra en United Parcel Service of America Inc. (UPS) c. Gobierno de Canadá, bajo el Reglamento de Arbitraje de la CNUDMI, Laudo sobre los Méritos, del 24 de mayo de 2007. El caso se refería al mantenimiento del monopolio del Correo de Canadá (Canada Post) con respecto a las pequeñas entregas de paquetería, que tenía su base en un estatuto que, en efecto, impedía al inversor de realizar negocios en esa jurisdicción. Un aspecto notable de la narración fáctica

42 Vid. también William Ralph Clayton, William Richard Clayton, Douglas Clayton, Daniel Clayton y Bilcon of Delaware, Inc. c. el Gobierno de Canadá, CNUDMI, CPA Caso No. 2009-04, Decisión sobre Jurisdicción y Responsabilidad (17 de marzo de 2015), sosteniendo que «mientras que el artículo 1116 (2) infringe los actos que tuvieron lugar más de tres años antes de que se presentara la reclamación, los hechos anteriores a la cláusula de tres años, sin embargo, no son irrelevantes. Ellos pueden proporcionar antecedentes necesarios sobre el contexto para determinar si las violaciones se produjeron durante el período de tiempo elegible».

43 Vid. v.g., Salini c. Marruecos, Caso CIADI No. ARB/00/4, Decisión sobre Jurisdicción, párr. 5254 (2001). Schreuer, por su parte, observa que existen cinco «rasgos» típicos de «la mayoría de las operaciones» que han sido objeto de procedimientos del CIADI: (i) «una cierta duración» de la empresa; (ii) «cierta regularidad de beneficio y retorno»; (iii) una «asunción de riesgo»; (iv) un compromiso «sustancial» por parte del inversionista; y (v) alguna «importancia para el desarrollo del Estado receptor». 
subyacente a esa causa, en lo que se refiere a la cuestión del efecto excluyente de la prescripción pertinente, es que el marco legal anterior a la presentación de la reclamación por parte del inversor, establecía un plazo de tres años. El Tribunal en UPS calificó el grado en que un curso continuo de una conducta puede constituir incumplimientos nuevos y recurrentes que generan un nuevo período de prescripción. Sostuvo el Tribunal, específicamente que, en caso de incumplimiento continuado, el reclamante queda limitado a obtener la compensación que se cause únicamente dentro del plazo de los tres años (en el contexto del TLCAN) previos a la presentación de la reclamación:

Aunque constatamos que no existe un plazo límite para las reclamaciones, el plazo de prescripción sí tiene una aplicación particular ante un curso continuado de conducta. Si se establece una violación del TLCAN con respecto a cualquier reclamación en particular, cualquier obligación relacionada con las pérdidas que surjan con respecto a esa reclamación puede basarse únicamente en las pérdidas sufridas dentro de los tres años previos a la fecha en que se presentó la reclamación. Un curso continuado de conducta podría generar pérdidas de una dimensión diferente en momentos diferentes. Corresponde a los reclamantes establecer los daños y perjuicios asociados a las violaciones alegadas y la conducta continuada que debe incluir una demostración de daños y perjuicios, no desde el inicio del curso de conducta, sino únicamente de la conducta que se produzca dentro del plazo permitido por el artículo 1116 (2). Sin embargo, esto no es una cuestión que debamos abordar en este punto aparte de las reivindicaciones específicas $^{44}$ [énfasis añadido].

Mientras que el tribunal de UPS finalmente rechazó las reclamaciones basadas en el TLCAN sobre el fondo, el laudo sirve como autoridad fundacional para un curso continuado de conducta o enfoque de «daño continuado» ${ }^{45}$.

$\mathrm{Al}$ igual que con los tribunales que tratan de ampliar el período de prescripción a fin de comprender más ampliamente los hechos reales presun-

44 UPS c. Canada, párr. 30.

45 El derecho consuetudinario de Estados Unidos ha reconocido desde hace mucho tiempo una doctrina continua de daño extracontractual (continuing tort doctrine) que impone la suspensión de las leyes nacionales de prescripción. Vid. v.g, National Railroad Passenger Corp. v Morgan, 536 U.S. 101 (2002); United Airlines c. Evans, 431 U.S. 553 (1977); y, Hilao c. Estate of Marcos, 103 F.3d 767, 773 (9th Cir. 1996). Ver también Elad Peled, Retbinking The Continuing Violation Doctrine: The Application Of Statutes Of Limitations To Continuing Tort Claims, 41 Ohio N.U. L. Rev. 343 (2015). 
tamente gobernados por el plazo de prescripción, un análisis de los daños continuados subraya la necesidad rudimentaria de un período de prescripción más largo o bien de un período suficientemente flexible para ampliar sus términos cuando las circunstancias así lo justifiquen. La configuración de una inversión, el acto regulatorio o los actos en cuestión, la naturaleza de los daños alegados, las circunstancias particulares que configuran un caso y la norma o normas de protección supuestamente violadas, pueden sugerir que la aplicación del período de tres años, que tiene su origen en la importación de la legislación nacional-doméstica, en un tratado es simplemente inadecuada. En lugar de abordar la causa conceptual de un déficit pragmático, los tribunales ad hoc, encargados de procesar un conjunto individual de reclamaciones, relativas exclusivamente a una disputa, no pueden sino limitarse a tratar el síntoma y no la enfermedad subyacente. Un enfoque de daños continuados simplemente mitiga los efectos sistémicos de una deficiencia conceptual.

\section{B. Un estándar de razonabilidad puede ser discernido con respecto a los períodos de prescripción en el Derecho Internacional Público}

No existe ninguna autoridad que establezca una norma de derecho internacional consuetudinario equivalente al período de prescripción extintiva. Del mismo modo, el derecho internacional público no identifica una norma operativa que pueda aplicarse a cuestiones o análisis de períodos de prescripción. El escrutinio del corpus de los laudos arbitrales basados en tratados que abordan la cuestión del período de prescripción, sin embargo, revela la aplicación recurrente de un criterio de «razonabilidad». Esta norma se ha aplicado sin referencia a la legislación nacional y en situaciones donde el tratado en cuestión carece de un período de prescripción.

El análisis en Wena Hotels Limited c. la República Arabe de Egipto, Caso No. $\mathrm{ARB} / 98 / 4$ de CIADI, es útil. Allí, el demandante presentó una reclamación bajo el APPRI entre el Reino Unido y Egipto relativa a la incautación de dos propiedades en 1991 en el sector de hostelería, los hoteles Luxor y Nilo. El Demandado argumentó que la demanda debía ser desestimada de inmediato, por cuanto el artículo 172(1) del Código Civil Egipcio específicamente indicaba que «un caso presentado por daños y perjuicios, reclamados por un acto ilegal, quedaría prescrito en un lapso de tres años, contados a partir del día en que la persona agraviada se enterara de que los daños se produjeron y de 
quién es la persona responsable. A todo evento, el caso caerá en el lapso de prescripción de quince años desde del día en que se produzca el acto ilícito» ${ }^{46}$.

Más aun, la demandada argumentó además que, aunque el Tribunal se abstuviera de aplicar la ley domestica sobre prescripción extintiva de Egipto, el Tribunal «tendría todavía la facultad discrecional de determinar si se había producido una demora excesiva en la presentación de las reclamaciones de éste reclamante ante CIADI». ${ }^{47}$ En Wena la solicitud de arbitraje se registró en 1998, siete años después de que hubieran ocurrido las medidas expropiatorias de los hoteles Luxor y Nilo. El Tribunal no admitió la defensa basada en la prescripción y determinó en ese procedimiento que, de acuerdo con los hechos específicos de ese caso, el período de siete años que separaba la maduración de las reclamaciones y el registro efectivo de una solicitud de arbitraje ante CIADI era eminentemente razonable. Se consagró a un análisis de dos extremos que (i) trazó el desarrollo del principio general de que no hay prescripción extintiva en el derecho internacional, y (ii) analizó la razonabilidad de demorar la presentación de la reclamación por siete años, pero lo hizo dentro de un marco de equidad ${ }^{48}$.

En primer lugar, el Tribunal utilizó el apoyo analítico de Alan Craig c. Ministerio de Energía de Irán, Cámara Tres del Tribunal de Reclamaciones entre Estados Unidos e Irán donde, a pesar de la aplicabilidad de la ley iraní, el Tribunal declinó aplicar un estatuto de prescripción de ese país y señaló que «las leyes municipales de prescripción no han sido consideradas vinculantes para las reclamaciones ante tribunales internacionales, aunque tales períodos pueden ser tomados en cuenta por el Tribunal para determinar el efecto de una demora irrazonable en la tramitación de una reclamación $»^{49}$ [énfasis añadido]. Además, el Tribunal reconoció que este principio era antiguo y que tenía base en el venerable caso Gentini en el que, como indicó anteriormente el autor, la Comisión Mixta de Reclamaciones señaló que los tribunales internacionales son libres de considerar principios equitativos de prescripción en la evaluación de reclamaciones vetustas ${ }^{50}$.

46 Wena c. Egipto, en párr. 102, citando el Código Civil Egipcio.

47 Idem.

48 Vid. Wena c. Egipto, en párr. 102-09

49 Idem en párr. 106 citando a Alan Craig c. Ministerio de Energía de Irán, Tribunal de Reclamaciones entre Estados Unidos e Irán 280 (1984) [Anexo W155], y también George Aldrich, The furisprudence of the Iran-United States Claims Tribunal 480-482 (1996) [Anexo E-M47].

50 Idem en párr. 106. 
El Tribunal Wena primero tomó prestada las opiniones de la Comisión Mixta de Reclamaciones entre Italia y Venezuela y luego realizó el análisis de razonabilidad en dos partes, dentro de un marco de equidad. Dos proposiciones fueron identificadas como relevantes. Primero, ¿fue violada la noción de «reposo»? Específicamente, la demandada la República Árabe de Egipto «razonablemente creería que una disputa ha sido abandonada o pospuesta desde hace mucho tiempo [de tal manera que Egipto] no debería ser sorprendido por la subsiguiente resurrección [de la disputa] ${ }^{51}$. En segundo lugar, el Tribunal se preguntó en qué grado el intervalo de siete años entre la presentación de la reclamación y el registro de la solicitud de arbitraje causó algún daño. Respondió ambas preguntas negativamente ${ }^{52}$.

\section{UN CAMBIO DE PARADIGMA CON BASE EN LAS POLÍTICAS DEL DERECHO INTERNACIONAL PÚBLICO DE PROTECCIÓN DE INVERSIONES}

La situación actual de la LPD en el marco del derecho internacional público de protección de inversiones no es viable. De hecho, los déficits en el enfoque teórico y práctico de la doctrina son tales que el régimen moderno que gobierna la doctrina en el derecho internacional de protección de inversiones, en realidad da lugar a la inseguridad y la incertidumbre. Sin embargo, la jurisprudencia y los escritos relativos al funcionamiento de la LPD en el derecho internacional en general al unísono afirman que los dos objetivos primordiales de la doctrina de la prescripción extintiva son la seguridad y la certeza.

Cuatro factores fundamentales explican la incertidumbre y la inseguridad que caracterizan el régimen de la doctrina contemporánea. En primer lugar, la LPD en el derecho internacional de protección de inversiones se basa en la importación al mayor de la legislación nacional-doméstica. Concretamente: (i) el interés económico de los Estados exportadores de capital; (ii) las normas nacionales-domésticas del derecho de propiedad; (iii) los principios nacionales-domésticos del derecho de contratos; y (iv) la ley nacional-doméstica sobre negligencia, todos ellos subyacen en el moderno régimen del período de prescripción extintiva. En segundo lugar, el marco de la doctrina contemporánea en el derecho internacional de protección de inversiones simplemente

51 Idem en párr. 105.

52 Idem en párr. 106. 
se formó sin tener en cuenta los múltiples objetivos -de política- directos y colaterales que componen esta área del derecho. Esta deficiencia es de naturaleza fundacional. En tercer lugar, la rúbrica de la doctrina actual dentro del derecho internacional de protección de inversiones está fragmentada. Los APPRIs de primera generación, que aquí se definen como elaborados entre 1959 y 1993, no contienen ningún período de prescripción. Por lo tanto, las controversias que surjan de esos 563 APPRIs no contienen guía alguna con respecto a: (i) la posible preservación de las reclamaciones a perpetuidad; (ii) la incorporación de los términos de los períodos de prescripción que se derivan del derecho nacional-doméstico; o (iii) la inclusión de tales períodos en el procedimiento, con base en la discreción arbitral. Las tres posibilidades son fundamentalmente defectuosas. Los APPRIs de segunda generación (APPRI modernos) que aquí se definen como los suscritos entre 1994 y el año de este escrito (2017) reflejan que sólo ciento seis de un total de mil cuatrocientos noventa y ocho (1.498) APPRIs, equivalentes a 7,08\% ${ }^{53}$ contienen un período de prescripción ${ }^{54}$. Por otra parte, el $7.08 \%$ que presentaba un período de prescripción comprendía términos que oscilaban entre dos y cinco años, que se ajustaban a estándares de protección de inversión extranjera. Tanto la duración de estos términos como los diferentes términos que se aplican a los mismos estándares de protección son -práctica y conceptualmente- problemáticos.

Dentro de la generación moderna de APPRIs también encontramos que la ubicación del período de prescripción difiere según el tratado. A veces se hace referencia al período de prescripción conjuntamente con el estándar de protección pertinente al que se aplica ${ }^{55}$. En tales casos, el período de pres-

53 Una vez que añadimos a los APPRIs el número total de TIPs que contienen un período de prescripción, las cifras ascienden a un total de 1.524, donde 132 contienen términos de prescripción, es decir, el 8,66\%. De conformidad con la UNCTAD (siglas en inglés de la Conferencia de las Naciones Unidas sobre Comercio y Desarrollo), en su International Investment Agreements Navigator, entre 1994 y 2017, 1524 APPRIs y TIPs entraron en vigor.

54 Vid. Anexo A.

55 Vid. v.g, el Tratado de Libre Comercio entre Colombia y Estados Unidos, donde las provisiones para inversiones se encuentran en el Capítulo Diez, y el plazo de las prescripción específicamente en el Art. 10.18. Sin embargo, el Capítulo Doce, relativo a «Servicios Financieros» en el Art. 12.1.2 (b) establece que «la Sección B (Solución de Controversias Inversionista-Estado) del Capítulo Diez (Inversión) se incorpora y forma parte de este Capítulo únicamente para las reclamaciones de que una Parte ha violado los Artículos 10.7 (Expropiación y Compensación), 10.8 (Transferencias), 10.12 (Denegación de Beneficios) o bien 10.14 (Formalidades Especiales y Requisitos de Información), como se incorpora en este Capítulo». El art. 12.1.2(b) no mencionó el período de prescripción. En este sentido, no hay un período de prescripción aplicable al capítulo de servicios financieros. 
cripción debe interpretarse como sustantivo, es decir, formando parte de la norma de protección de la inversión. En otros APPRI modernos el período de prescripción se coloca conjuntamente con los predicados jurisdiccionales y los derechos procesales. ${ }^{56}$ En esos casos, el período de prescripción debe interpretarse como procedimental. Por lo tanto, encontramos que, bajo el actual «legado», la LPD dentro del derecho internacional de protección de inversiones puede ser interpretada como sustantiva y procesal aunque no se reconoce como tal. La no divulgación y la categorización conceptual de esta dualidad bajo el régimen existente es insuficiente debido a que crea incertidumbre e inseguridad respecto de la cláusula de la nación más favorecida (NMF) contenida en los tratados $^{57}$.

En cuarto lugar, dos líneas conflictivas de autoridad sobre una cuestión tan rudimentaria como si el derecho internacional consuetudinario reconoce la LPD, nublan el derecho internacional consuetudinario con respecto a este principio fundamental. Los efectos negativos de estas cuatro características del actual régimen LPD en el derecho internacional de protección de las inversiones se agravan y empeoran debido a la naturaleza del marco ad hoc del arbitraje entre inversores y Estados. Estos tribunales luchan por injertar la relatividad y la flexibilidad en lo que, esencialmente, es un paradigma estático e inflexible que deja poco espacio para la consideración de políticas o la reformulación de paradigmas normativos. Los tribunales están encargados

56 Vid. el APPRI entre Colombia y el Reino Unido, donde el período de prescripción se encuentra en el art. IX, titulado «Solución de controversias entre una Parte Contratante y un Inversionista de la otra Parte Contratante», en el que se enumeran derechos procesales y no derechos sustantivos.

57 Hay escenarios en los que la cláusula NMF de un tratado permite importar un estándar sustantivo de protección de otro tratado, excluyendo al mismo tiempo el período de prescripción de la norma de protección importada. Tal sería el caso, por ejemplo, del Capítulo 12 del Tratado de Libre Comercio entre Colombia y Estados Unidos, la cláusula NMF y el estándar de protección del trato justo y equitativo (FET, por sus siglas en inglés) que figura en el APPRI entre Colombia y el Reino Unido. El APPRI entre Colombia y el Reino Unido contiene el estándar de FET en el Art. II, titulado «Promoción, Admisión y Protección de Inversiones» y el término presuntamente correspondiente de prescripción en el Art. IX, relativo a la «Solución de controversias entre una Parte Contratante y un Inversionista de la otra Parte Contratante», que pasa a formar parte de los derechos procesales en la resolución procesal de disputas. En este escenario, el período de prescripción constituye un término procesal.

Existen, sin embargo, escenarios en los que la cláusula NMF de un tratado podrá importar un período de prescripción de un segundo tratado en el que ese período se ubique junto al estándar de protección que se importa. Bajo este escenario, el período de prescripción constituiría un derecho sustantivo. 
del funcionamiento práctico de la «resolución de problemas» y no de la «formulación de políticas».

Tales incertidumbres obligan a una segunda vista y revisión completa de la LPD dentro del derecho internacional de la protección de las inversiones.

\section{A. Un enfoque prescriptivo}

A continuación se presenta una lista no exhaustiva de proposiciones que deberían formar parte de cualquier análisis de la LPD. Este catálogo de premisas tiene como base el supuesto de que los desarrollos doctrinales en cualquier campo del derecho en general, y ciertamente en el derecho internacional de protección de inversiones, requieren que el precepto doctrinal en cuestión tenga una relación racional con el objeto y los objetivos del régimen jurídico en cuestión. Las siguientes quince (15) proposiciones pretenden cumplir este máximo estándar.

Primero, se concederá al inversionista una presunción refutable de que una reclamación ha sido presentada a tiempo. Por el contrario, una reclamación que vaya más allá de los términos establecidos en el tratado aplicable no dará lugar a una presunción prima facie de negligencia por parte del inversionista por no haber presentado la reclamación antes. ${ }^{58}$

Segundo, la LPD dentro del derecho internacional de la protección de inversiones necesita expresar uniformidad. Esta uniformidad debe ser compatible con (i) cualquier norma conceptual relativa a la aplicación de un período de prescripción, así como (ii) las normas específicas de protección sustantiva.

Tercero, la LPD no debe descansar exclusivamente sobre las normas nacionales-domésticas adoptadas del derecho de propiedad, los contratos y los daños. Estos principios jurídicos no se desarrollaron para aplicarse a reclamaciones derivadas de una supuesta violación de una norma de protección con base en un tratado, causada por el ejercicio excesivo o ilícito de la soberanía

58 La literatura sobre el LPD habla en términos de «negligencia» al no presentar una reclamación. Este entendimiento de la negligencia surge de los fundamentos de la ley nacional-doméstica. La negligencia del derecho consuetudinario se basa en elementos relativos a: (i) deber/ obligación, que; (ii) fue trasgredida o incumplida; (iii) que da lugar a daños; y (iv) en el cual los daños deben tener una relación causal (inmediata/directa) con el incumplimiento del deber. No obstante, en un régimen jurídico internacional, estos elementos no pueden transponerse fácilmente porque los deberes y las relaciones causales entre inversores y Estados difieren de los que existen entre particulares. 
reglamentaria de un Estado: de allí, la incongruencia teórica y práctica de la capacidad de la LPD para fomentar certeza y seguridad.

Cuarto, la LPD debe analizarse, en su caso, en el contexto de la doctrina de la proporcionalidad del derecho internacional. Un enfoque «todo o nada» de la aplicación de la LPD, para desestimar una reclamación sin los beneficios de haber adoptado un enfoque global para considerar los factores pertinentes relacionados con este campo del derecho (protección de las inversiones) sólo puede fomentar incertidumbre e inseguridad.

Quinto, cualquier análisis de la aplicación de la LPD debe considerar hasta qué punto es posible recurrir a un tribunal no doméstico durante el plazo en cuestión. A este respecto, el Tribunal debe ser particularmente flexible en pro de permitir que se presenten las reclamaciones, en particular cuando se esté procesando una demanda por Denegación de Justicia.

Sexto, el universo específico de las consecuencias previsibles, económicas o en especie, derivadas de la presunta violación de una controvertida norma de protección debe sopesarse contra el despido de una reclamación con base en la prescripción. Las consideraciones de política relacionadas con: (i) el sector industrial en cuestión; (ii) la contribución del inversor a ese sector; y (iii) el grado en que la naturaleza de la inversión hace que la misma fuese más vulnerable al ejercicio excesivo o ilícito de la soberanía reglamentaria, todo esto debe ser considerado.

Séptimo, la naturaleza única de las inversiones generalmente debe ser considerada en la aplicación de un análisis de prescripción. Por ejemplo, una mayor flexibilidad en la aplicación de la doctrina a favor de un inversor debe producirse en aquellos casos en que la inversión depende en particular de la protección reguladora del Estado receptor.

Octavo, deben considerarse las circunstancias relativas a la capacidad del reclamante para presentar las reclamaciones, incluidas la coacción, bien sea económica, política, social o de otra índole, así como la capacidad de cobrarle al Estado receptor. Este análisis también debe evaluar la percepción subjetiva, pero razonablemente basada en el criterio del reclamante de que la presentación de una reclamación ante un tribunal internacional probablemente haría que el Estado tomase represalias contra reclamante o sus afiliados.

Noveno, los efectos de las disparidades asimétricas y de recursos entre el reclamante-inversor y el Estado receptor, según sea el caso, deben considerarse. No se puede suponer que la relación inversor-Estado receptor es una de igualdad entre partes.

Décimo, la formulación o aplicación de la LPD debe considerar las contribuciones macroeconómicas de la inversión a ser retirada o bien el efecto de 
enfriamiento que la desestimación del reclamo pueda tener sobre los futuros inversionistas, particularmente con respecto al sector industrial en cuestión.

Undécimo, la formulación o aplicación de la LPD debe considerar las contribuciones microeconómicas de la inversión a ser retirada o el efecto de enfriamiento que la desestimación del reclamo pueda tener sobre los futuros inversionistas, particularmente con respecto al sector industrial en cuestión.

Duodécimo, el arbitraje con base en un tratado debería regirse por una política que favorezca el acceso liberal a una metodología de solución de controversias. Siempre debe haber una presunción a favor del acceso a un foro internacional neutral. Los derechos procesales en los tratados se frustran en los casos en los que se prevé un plazo de prescripción que sería similar a la ley nacional-doméstica en los ámbitos de los contratos, el derecho de propiedad, la negligencia o el derecho de responsabilidad civil por daño. Por lo tanto, la formulación y aplicación de la LPD requiere la consideración de las consecuencias del presunto acto regulador sobre la inversión extranjera directa con respecto al Estado receptor y otras economías en desarrollo. La aplicación de la LPD debe ser atenuada en los casos en que el presunto acto reglamentario haya causado o continúe causando daños y perjuicios de manera recurrente.

Decimotercero, desde una perspectiva analítica, la LPD no debe ser conceptualizada, clasificada y aplicada como sustantiva o procesal. En lugar de ello, la LPD, al igual que la dualidad onda-partícula que se une al fenómeno físico de la naturaleza de la luz, debe considerarse como dotada de una doble característica dependiendo de la ubicación del período de prescripción en un tratado en particular. Así, es apropiado permitir la flexibilidad conceptual que hace posible que la LPD sea tratada como procesal o sustantiva. Esta transparencia de naturaleza y finalidad fomenta la seguridad y la certeza.

Decimocuarto, el actual régimen de dos a cinco años que se encuentra en los APPRIs de segunda generación -que tienen su génesis en la legislación nacional-doméstica- simplemente es demasiado abreviado en plazo como para servir a manera de término de prescripción. Este cálculo generalmente puede funcionar en el contexto de transacciones realizadas en condiciones de igualdad entre entidades privadas o entre particulares. No se puede suponer que el mismo término de prescripción se aplicaría y produciría beneficios similares en el contexto de las asimetrías que impregnan la relación, única y dispareja, entre un actor privado y un Estado. Términos de prescripción más generosos y calificados contribuirán a nivelar el campo de juego.

Decimoquinto y último, al determinar la aplicación de un período de prescripción que pueda causar que se desestime una reclamación, el tribunal 
debe considerar cualquier prueba que demuestre que un reclamante competente deliberadamente retuvo la presentación de una reclamación para beneficiarse de la desaparición o disminución de pruebas potencialmente adversas para el enjuiciamiento de una reclamación con base en el incumplimiento de un estándar de protección de un tratado. El tribunal también deberá examinar si la presentación tardía del reclamo causó o causaría daños o perjuicios al demandado.

\section{CONCLUSIÓN}

Un estándar uniforme es un imperativo. De los aproximadamente tres mil APPRIs suscritos, sólo ciento seis tienen un período de prescripción. Esta configuración significa que en aproximadamente el 96,5\% los casos que tienen que ver con los APPRIs, los tribunales son libres de crear un período de prescripción extintiva sin el beneficio de estándar alguno. Alternativamente, los tribunales se encuentran en la posición insostenible de no aplicar período de prescripción alguno. Ninguna de estas opciones es viable porque fomentan la incertidumbre y la inseguridad.

La reforma es necesaria. Sin embargo, una revisión de los fundamentos teóricos y prácticos de la LPD no puede volver al modelo heredado, que busca el apoyo analítico en la ley nacional-doméstica. Del mismo modo, un paradigma basado en las aspiraciones de los Estados exportadores de capital, por sí solo, no es funcional.

El derecho internacional de la protección de las inversiones debe tener en cuenta el derecho internacional, en particular después del advenimiento de la globalización económica y la integración transnacional. Los elementos de la LPD deben basarse en las políticas y aspiraciones del propio derecho de protección de inversiones. De lo contrario, las posiciones relativas de poder entre las partes y el acceso a los recursos no pueden armonizarse en un equilibrio que concilie mejor las obligaciones aparentemente incompatibles de (i) proteger las inversiones extranjeras, y (ii) participar en la soberanía regulatoria. Abandonar el legado y su tipo de análisis es difícil y lleno de desafíos. Sin embargo, en esta etapa del desarrollo del comercio mundial y la integración de ciento noventa y dos Estados en una economía transnacional singular y -supuestamente- uniforme, no hay otra opción. La promesa de LPD de fomentar la seguridad y la certeza es la única expectativa válida. 
Anexo

\section{Tratados en vigor con plazos de prescripción extintiva}

(Ordenado por la fecha de suscripción)

\begin{tabular}{|c|c|c|c|}
\hline & $\begin{array}{l}\text { Acuerdo de Prom. y Prot. de Inversión } \\
\text { (APPRIs) }\end{array}$ & $\begin{array}{c}\text { Plazo } \\
\text { (en años) }\end{array}$ & Año \\
\hline 1. & Canadá - Ucrania & 3 & 1994 \\
\hline 2. & México - Suiza & 3 & 1995 \\
\hline 3. & Canadá - Trinidad and Tobago & 3 & 1995 \\
\hline 4. & Canadá - Filipinas & 3 & 1995 \\
\hline 5. & Canadá - Ecuador & 3 & 1996 \\
\hline 6. & Barbados - Canadá & 3 & 1996 \\
\hline 7. & Canadá - Venezuela & 3 & 1996 \\
\hline 8. & Canadá - Panamá & 3 & 1996 \\
\hline 9. & Canadá - Egipto & 3 & 1996 \\
\hline & Argentina - México & 4 & 1996 \\
\hline & Canadá - Tailandia & 3 & 1997 \\
\hline & Canadá - Croacia & 3 & 1997 \\
\hline 13. & Canadá - Líbano & 3 & 1997 \\
\hline & Armenia - Canadá & 3 & 1997 \\
\hline & Canadá - Uruguay & 3 & 1997 \\
\hline & Canadá - Costa Rica & 3 & 1998 \\
\hline & México - Holanda & 3 & 1998 \\
\hline & Austria - México & 4 & 1998 \\
\hline & Alemania - México & 4 & 1998 \\
\hline & Bélgica-Luxemburgo Unión Económica - México & 3 & 1998 \\
\hline & France - México & 4 & 1998 \\
\hline & Finlandia-México & 4 & 1999 \\
\hline & México - Uruguay & 3 & 1999 \\
\hline & México - Portugal & 3 & 1999 \\
\hline & Austria - Cuba & 5 & 2000 \\
\hline & Austria - Uzbekistán & 5 & 2000 \\
\hline
\end{tabular}




\begin{tabular}{|c|c|c|c|}
\hline & $\begin{array}{l}\text { Acuerdo de Prom. y Prot. de Inversión } \\
\text { (APPRIs) }\end{array}$ & $\begin{array}{c}\text { Plazo } \\
\text { (en años) }\end{array}$ & Año \\
\hline 27. & Austria - Azerbaiyán & 5 & 2000 \\
\hline 28. & Austria - Bosnia y Herzegovina & 5 & 2000 \\
\hline 29. & México - Suecia & 4 & 2000 \\
\hline 30. & República de Corea - México & 3 & 2000 \\
\hline 31. & Austria - Bangladesh & 5 & 2000 \\
\hline 32. & Austria - Irán & 5 & 2001 \\
\hline 33. & Cuba - México & 3 & 2001 \\
\hline 34. & Austria - Belice & 5 & 2001 \\
\hline 35. & Austria-Georgia & 5 & 2001 \\
\hline 36. & República Checa - México & 3 & 2002 \\
\hline 37. & Austria - Malta & 5 & 2002 \\
\hline 38. & Austria - Namibia & 5 & 2003 \\
\hline 39. & Austria - Yemen & 5 & 2003 \\
\hline 40. & República de Corea - Vietnam & 3 & 2003 \\
\hline 41. & Austria - Etiopía & 5 & 2004 \\
\hline 42. & Colombia - España & 3 & 2005 \\
\hline & Islandia - México & 3 & 2005 \\
\hline & Australia - México & 4 & 2005 \\
\hline & Bélgica-Luxemburgo Unión Económica - Perú & 3 & 2005 \\
\hline & Estados Unidos de América - Uruguay & 3 & 2005 \\
\hline & Austria - Guatemala & 5 & 2006 \\
\hline & México - Reino Unido & 3 & 2006 \\
\hline & Colombia - Suiza & 5 & 2006 \\
\hline & México - Trinidad and Tobago & 3 & 2006 \\
\hline 51. & México - España & 3 & 2006 \\
\hline 52. & Canadá - Perú & 3 & 2006 \\
\hline & Bélgica-Luxemburgo Unión Económica - R. of Corea & 5 & 2006 \\
\hline & Azerbaiyán - Hungría & 3 & 2007 \\
\hline & India - México & 3 & 2007 \\
\hline & Camboya - Japón & 3 & 2007 \\
\hline
\end{tabular}




\section{Acuerdo de Prom. y Prot. de Inversión (APPRIs)}

\section{Plazo (en años)}

Año

\begin{tabular}{clcc} 
57. & China - República de Corea & 3 & 2007 \\
\hline 58. & Colombia - Perú & 39 meses $^{*}$ & 2007 \\
\hline 59. & Japón - República Democrática Popular de Laos & 3 & 2008 \\
\hline 60. & Ruanda - Estados Unidos de América & 3 & 2008 \\
\hline 61. & China - México & 3 & 2008 \\
\hline 62. & Bielorrusia - México & 3 & 2008 \\
\hline 63. & Japón - Perú & 3 & 2008 \\
\hline 64. & China - Colombia & 3 & 2008 \\
\hline 65. & Canadá - Letonia & 3 & 2009 \\
\hline 66. & Canadá - República Checa & 3 & 2009 \\
\hline 67. & Canadá - Romania & 3 & 2009 \\
\hline 68. & Uruguay - Vietnam & $2^{* *}$ & 2009 \\
\hline 69. & República de Corea - Ruanda & 3 & 2009 \\
\hline 70. & Canadá - Jordania & 3 & 2009 \\
\hline 71. & República de Corea - Uruguay & 3 & 2009 \\
\hline 72. & Colombia - India & 3 & 2009 \\
\hline 73. & México - Singapur & 3 & 2009 \\
\hline 74. & San Vicente y las Granadinas - Taiwán & 3 & 2009 \\
\hline 75. & Austria - Kazakstán & 5 & 2010 \\
\hline 76. & Colombia - Reino Unido & 5 & 2010 \\
\hline 77. & Chile - Uruguay & 3 & 2010 \\
\hline 78. & Egipto - Suiza & 5 & 2010 \\
\hline 79. & Austria - Tayikistán & 5 & 2010 \\
\hline 80. & China - Uzbekistán & 3 & 2011 \\
\hline 81. & Japón - Papúa Nueva Guinea & 5 & 2011 \\
\hline 82. & Colombia - Japón & 3 \\
\hline 83. & Canadá - Kuwait & 2011 \\
\hline 84. & Japón - Kuwait & 3 & \\
\hline & & 3 & 3 \\
\hline
\end{tabular}

* El APPRI Colombia - Perú es el único tratado con un plazo de tres años y tres meses.

** El APPRI Uruguay - Vietnam es el tratado con el período de prescripción más corto, dos años. 


\begin{tabular}{clcc} 
& \multicolumn{1}{c}{$\begin{array}{c}\text { Acuerdo de Prom. y Prot. de Inversión } \\
\text { (APPRIs) }\end{array}$} & $\begin{array}{c}\text { Plazo } \\
\text { (en años) }\end{array}$ & Año \\
\hline 85. & Iraq - Japón & 5 & 2012 \\
\hline 86. & Suiza - Túnez & 5 & 2012 \\
\hline 87. & Bahréin - México & 3 & 2012 \\
\hline 88. & Benín - Canadá & 3 & 2013 \\
\hline 89. & Kuwait - México & 3 & 2013 \\
\hline 90. & Japón - Saudí Arabia & 5 & 2013 \\
\hline 91. & Canadá - Tanzania & 3 & 2013 \\
\hline 92. & Japón - Mozambique & 3 & 2013 \\
\hline 93. & Guatemala - Trinidad y Tobago & 3 & 2013 \\
\hline 94. & India - Emiratos Árabes Unidos & 5 & 2013 \\
\hline 95. & Japón - Myanmar & 3 & 2013 \\
\hline 96. & Camerún - Canadá & 3 & 2014 \\
\hline 97. & Georgia - Suiza & 5 & 2014 \\
\hline 98. & Egipto - Mauricio & 3 & 2014 \\
\hline 99. & Canadá - Serbia & 3 & 2014 \\
\hline 100. & Japón - Kazakstán & 3 & 2014 \\
\hline 101. & Canadá - Senegal & 3 & 2014 \\
\hline 102. & Canadá - Mali & 3 & 2014 \\
\hline 103. & Canadá - Costa de Marfil & 3 & 2014 \\
\hline 104. & Japón - Ucrania & 3 & 2015 \\
\hline 105. & Canadá - Hong Kong China SAR & 3 & 2016 \\
\hline 106. & Canadá - Mongolia & 3 & 2016 \\
\hline & & &
\end{tabular}




\begin{tabular}{clcc} 
& \multicolumn{1}{c}{$\begin{array}{c}\text { Tratados con Provisiones de Inversión } \\
\text { (TIPs) }\end{array}$} & $\begin{array}{c}\text { Plazo } \\
\text { (en años) }\end{array}$ & Año \\
\hline 1. & NAFTA (TLCAN) & 3 & 1994 \\
\hline 2. & Singapur - Estados Unidos de América TLC & 3 & 2003 \\
\hline 3. & Chile - Estados Unidos de América TLC & 3 & 2003 \\
\hline 4. & Marruecos - Estados Unidos de América TLC & 3 & 2004 \\
\hline 5. & RD-CAFTA & 3 & 2004 \\
\hline 6. & Omán - Estados Unidos de América TLC & 3 & 2006 \\
\hline 7. & Perú - Estados Unidos de América TLC & 3 & 2006 \\
\hline 8. & Colombia - Estados Unidos de América & 3 & 2006 \\
\hline 9. & Panamá - Estados Unidos de América TLC & 3 & 2007 \\
\hline 10. & India - Corea CEPA & 3 & 2009 \\
\hline 11. & India - Malaysia TLC & 3 & 2011 \\
\hline 12. & China, Japón, Corea, Tratado de Inversión Trilateral. & 3 & 2012 \\
\hline 13. & Colombia - Republica of Corea TLC & 3 y 6 meses* & 2013 \\
\hline 14. & Colombia - Costa Rica TLC & 3 & 2013 \\
\hline 15. & Nueva Zelandia - Taiwán ECA & 3 & 2013 \\
\hline 16. & Canadá - Honduras TLC & 3 & 2013 \\
\hline 17. & Alianza del Pacifico Protocolo Adicional & 3 & 2014 \\
\hline 18. & México - Panamá TLC & 3 & 2014 \\
\hline 19. & Australia - República de Corea TLC & 3 & 2014 \\
\hline 20. & Canadá - República de Corea TLC & 3 & 2014 \\
\hline 21. & Japón - Mongolia EPA & 3 & 2015 \\
\hline 22. & República de Corea - Nueva Zelandia TLC & 2015 \\
\hline 23. & República de Corea - Vietnam TLC & 2015 \\
\hline 24. & Unión Económica de Eurasia - Vietnam TLC & 2015 \\
\hline 25. & China - República de Corea & 3 & 2015 \\
\hline 26. & Australia - China TLC & 3 & 2015 \\
\hline & & 3 & 2015 \\
\hline
\end{tabular}

* El Acuerdo de Libre Comercio entre Colombia y la República de Corea contiene un período de prescripción de tres años y seis meses, al igual que el de la República de Corea - Nueva Zelandia.

** El TLC entre Australia y China especifica claramente que «ninguna reclamación podrá ser sometida a arbitraje en virtud de esta Sección si han transcurrido más de tres años a partir de la fecha en que el reclamante adquirió por primera vez, o debería haberlo adquirido, el conocimiento del incumplimiento alegado en virtud del Artículo 9.12.2... para las reclamaciones presentadas en virtud del Artículo 9.12.2 (a)...». Asimismo, un plazo de cuatro años para las reclamaciones presentadas bajo el Artículo 9.12.2 (b) durante el cual el reclamante presentará la reclamación en nombre de una empresa que posee o controla directa o indirectamente. 